NASA/TM-2012-217440

\title{
Modeling of Melt Growth During Carbothermal Processing of Lunar Regolith
}

\section{R. Balasubramaniam}

National Center for Space Exploration Research, Glenn Research Center, Cleveland, Ohio

S. Gokoglu

Glenn Research Center, Cleveland, Ohio

U. Hegde

National Center for Space Exploration Research, Glenn Research Center, Cleveland, Ohio 


\section{NASA STI Program . . . in Profile}

Since its founding, NASA has been dedicated to the advancement of aeronautics and space science. The NASA Scientific and Technical Information (STI) program plays a key part in helping NASA maintain this important role.

The NASA STI Program operates under the auspices of the Agency Chief Information Officer. It collects, organizes, provides for archiving, and disseminates NASA's STI. The NASA STI program provides access to the NASA Aeronautics and Space Database and its public interface, the NASA Technical Reports Server, thus providing one of the largest collections of aeronautical and space science STI in the world. Results are published in both non-NASA channels and by NASA in the NASA STI Report Series, which includes the following report types:

- TECHNICAL PUBLICATION. Reports of completed research or a major significant phase of research that present the results of NASA programs and include extensive data or theoretical analysis. Includes compilations of significant scientific and technical data and information deemed to be of continuing reference value. NASA counterpart of peer-reviewed formal professional papers but has less stringent limitations on manuscript length and extent of graphic presentations.

- TECHNICAL MEMORANDUM. Scientific and technical findings that are preliminary or of specialized interest, e.g., quick release reports, working papers, and bibliographies that contain minimal annotation. Does not contain extensive analysis.

- CONTRACTOR REPORT. Scientific and technical findings by NASA-sponsored contractors and grantees.
- CONFERENCE PUBLICATION. Collected papers from scientific and technical conferences, symposia, seminars, or other meetings sponsored or cosponsored by NASA.

- SPECIAL PUBLICATION. Scientific, technical, or historical information from NASA programs, projects, and missions, often concerned with subjects having substantial public interest.

- TECHNICAL TRANSLATION. Englishlanguage translations of foreign scientific and technical material pertinent to NASA's mission.

Specialized services also include creating custom thesauri, building customized databases, organizing and publishing research results.

For more information about the NASA STI program, see the following:

- Access the NASA STI program home page at http://www.sti.nasa.gov

- E-mail your question via the Internet to help@ sti.nasa.gov

- Fax your question to the NASA STI Help Desk at $443-757-5803$

- Telephone the NASA STI Help Desk at 443-757-5802

- Write to: NASA Center for AeroSpace Information (CASI) 7115 Standard Drive Hanover, MD 21076-1320 
NASA/TM-2012-217440

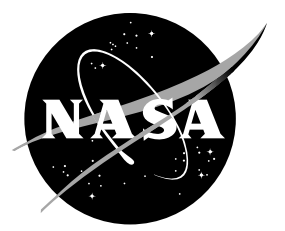

\section{Modeling of Melt Growth During Carbothermal Processing of Lunar Regolith}

\section{R. Balasubramaniam}

National Center for Space Exploration Research, Glenn Research Center, Cleveland, Ohio

S. Gokoglu

Glenn Research Center, Cleveland, Ohio

U. Hegde

National Center for Space Exploration Research, Glenn Research Center, Cleveland, Ohio

Prepared for the

50th Aerospace Science Conference

sponsored by the American Institute of Aeronautics and Astronautics

Nashville, Tennessee, January 9-12, 2012

National Aeronautics and

Space Administration

Glenn Research Center

Cleveland, Ohio 44135 


\section{Acknowledgments}

The authors thank Diane Linne, NASA Glenn Research Centeer, for useful discussions. The authors gratefully acknowledge the support of this work by the In-Situ Resource Utilization Project which is a part of the NASA Exploration Technology Development Program.

Trade names and trademarks are used in this report for identification only. Their usage does not constitute an official endorsement, either expressed or implied, by the National Aeronautics and Space Administration.

Level of Review: This material has been technically reviewed by technical management.

Available from

NASA Center for Aerospace Information 7115 Standard Drive

Hanover, MD 21076-1320
National Technical Information Service 5301 Shawnee Road Alexandria, VA 22312

Available electronically at http://www.sti.nasa.gov 


\title{
Modeling of Melt Growth During Carbothermal Processing of Lunar Regolith
}

\author{
R. Balasubramaniam \\ National Center for Space Exploration Research \\ Glenn Research Center \\ Cleveland, Ohio 44135 \\ S. Gokoglu \\ National Aeronautics and Space Administration \\ Glenn Research Center \\ Cleveland, Ohio 44135 \\ U. Hegde \\ National Center for Space Exploration Research \\ Glenn Research Center \\ Cleveland, Ohio 44135
}

The carbothermal processing of lunar regolith has been proposed as a means to produce carbon monoxide and ultimately oxygen to support human exploration of the moon. In this process, gaseous methane is pyrolyzed as it flows over the hot surface of a molten zone of lunar regolith and is converted to carbon and hydrogen. Carbon gets deposited on the surface of the melt, and mixes and reacts with the metal oxides in it to produce carbon monoxide that bubbles out of the melt. Carbon monoxide is further processed in other reactors downstream to ultimately produce oxygen.

The amount of oxygen produced crucially depends on the amount of regolith that is molten. In this paper we develop a model of the heat transfer in carbothermal processing. Regolith in a suitable container is heated by a heat flux at its surface such as by continuously shining a beam of solar energy or a laser on it. The regolith on the surface absorbs the energy and its temperature rises until it attains the melting point. The energy from the heat flux is then used for the latent heat necessary to change phase from solid to liquid, after which the temperature continues to rise. Thus a small melt pool appears under the heated zone shortly after the heat flux is turned on. As time progresses, the pool absorbs more heat and supplies the energy required to melt more of the regolith, and the size of the molten zone increases. Ultimately, a steady-state is achieved when the heat flux absorbed by the melt is balanced by radiative losses from the surface.

In this paper, we model the melting and the growth of the melt zone with time in a bed of regolith when a portion of its surface is subjected to a constant heat flux. The heat flux is assumed to impinge on a circular area. Our model is based on an axisymmetric three-dimensional variation of the temperature field in the domain. Heat transfer occurs only by conduction, and effects of convective heat transport are assumed negligible. Radiative heat loss from the surface of the melt and the regolith to the surroundings is permitted. We perform numerical computations to determine the shape and the mass of the melt at steady state and its time evolution. We first neglect the volume change upon melting, and subsequently perform calculations including it. Predictions from our model are compared to test data to determine the effective thermal conductivities of the regolith and the melt that are compatible with the data.

\section{Nomenclature}

$\begin{array}{ll}C_{p} & \text { Specific heat, } \mathrm{J} /(\mathrm{kg} \mathrm{K}) \\ d_{n} & \text { Normal displacement of the melt free surface, } \mathrm{m} \\ h & \text { Convective heat transfer coefficient, } \mathrm{W} /\left(\mathrm{m}^{2} \mathrm{~K}\right) \\ k & \text { Thermal conductivity, } \mathrm{W} /(\mathrm{m} \mathrm{K}) \\ \hat{L} & \text { Latent heat of melting, } \mathrm{J} / \mathrm{kg} \\ q_{0} & \text { Heat flux on the melt free surface, } \mathrm{W} / \mathrm{m}^{2}\end{array}$


$Q \quad$ Rate of energy impinging on the melt surface, $\mathrm{W}$

$r \quad$ Radial coordinate, $\mathrm{m}$

$R_{\text {beam }} \quad$ Radius of the beam of heat flux impinging the melt free surface, $\mathrm{m}$

$R_{\text {melt }} \quad$ Radius of the melt at its free surface, $\mathrm{m}$

$t \quad$ Time, s

$T \quad$ Temperature, $\mathrm{K}$

$T_{a} \quad$ Ambient temperature, $\mathrm{K}$

$T_{m} \quad$ Melting point, $\mathrm{K}$

$T_{s} \quad$ Temperature of the melt free surface, $\mathrm{K}$

$v_{n} \quad$ Normal velocity of the melt free surface, $\mathrm{m} / \mathrm{s}$

$V \quad$ Transformed temperature, $\mathrm{K}$

$V_{\text {melt }} \quad$ Melt volume, $\mathrm{m}^{3}$

$V_{\text {void }} \quad$ Volume of void space above melt, $\mathrm{m}^{3}$

$X \quad$ Location of the melting front, $\mathrm{m}$

Greek

$\alpha_{\text {abs }} \quad$ Absorption coefficient of the melt surface

$\rho \quad$ Density, $\mathrm{kg} / \mathrm{m}^{3}$

$\epsilon, \epsilon_{\mathrm{eff}} \quad$ Emissivity and effective emissivity of the melt and regolith surfaces

$\kappa \quad$ Thermal diffusivity, $\mathrm{m}^{2} / \mathrm{s}$

$\sigma \quad$ Stefan-Boltzmann constant, $\sigma=5.67 \times 10^{-8} \mathrm{~W} /\left(\mathrm{m}^{2} \mathrm{~K}^{4}\right)$

Subscript

melt Pertaining to the melt

reg Pertaining to the regolith

\section{Introduction}

A key element in NASA's plans for exploration involves the production of oxygen for life support as well as use as a propellant from in-situ resources. For example, Sanders et al. ${ }^{1}$ described NASA's plans for in-situ resource utilization on the Moon. Various processes are being considered for the extraction of oxygen that is available in the lunar regolith as oxides of various materials. These processes include reduction using hydrogen, molten salt electrolysis, and carbothermal processing. The carbothermal processing of lunar regolith using methane as the source for carbon was first performed by Rosenberg and co-workers at Aerojet in the 1960s (Rosenberg et al.) ${ }^{2}$ and developed further for lunar exploration by Orbital Technologies Corporation (ORBITEC). ${ }^{3}$

In the carbothermal process, gaseous methane is pyrolyzed above the hot surface of a molten zone of lunar regolith, depositing carbon on the surface and generating hydrogen which is carried away by the exiting stream of gas. The deposited carbon mixes with the melt and reacts with the metal oxides in it to produce carbon monoxide that bubbles out of the melt. Oxygen is ultimately produced by processing the carbon monoxide in reactors downstream. The amount of oxygen produced and its rate of production crucially depend on the volume of the melt. We have developed a chemical processing model of the carbothermal process ${ }^{4}$ to predict the rate of production of carbon monoxide, and the volume of the melt is an input parameter to that model.

In this paper we analyze the heat transfer aspects of the carbothermal process. Our goal is to predict the melt volume as it changes with time, as a function of the rate of heat input, surface radiative heat loss, and values of the thermophysical parameters, chiefly the thermal conductivity of the melt and regolith. We also determine the melt volume at steady state, if one exists. 


\section{Model}

\section{A. Background}

Figure 1 shows a schematic of the carbothermal process. A model of the processing of lunar regolith by this method is described in Ref[4]. In this analysis we focus on the heating and melting of the regolith. The regolith is contained in a suitably sized reaction chamber. The surface of the regolith is subjected to a heat source such as from a laser beam or a concentrated beam of solar energy. In tests performed terrestrially, the power and beam size are in the hundreds of watts and a few centimeters in diameter, respectively. For space applications, the beam power is expected to be around a kilowatt. The beam size will be larger, with the heat flux expected to be comparable to terrestrial tests. In our model, we assume that the heat flux impinges on the regolith surface over a circular area and the beam intensity is uniform (or axisymmetric at least). Before the regolith is heated, we assume that its temperature is initially uniform. For a boundary condition on the chamber walls, we either assume an adiabatic condition or set the temperature to the initial temperature of the regolith.

In order to minimize the radiative heat loss from the surface of the melt and the regolith, and maximize the volume of the melt for a given rate of heat input, a radiation shield is used that surrounds the top of the chamber. The radiation shield also provides an enclosure for containment of the gases (methane, carbon monoxide, etc.) involved in the carbothermal process. We do not include the radiation shield directly in the model. Its effect in reducing the radiative heat loss is incorporated by specifying an effective value (that is lower) for the emissivity of the surface of the melt and the regolith. While radiative heat loss is predominant, the model permits convective heat loss from the surface to the gas residing above it.

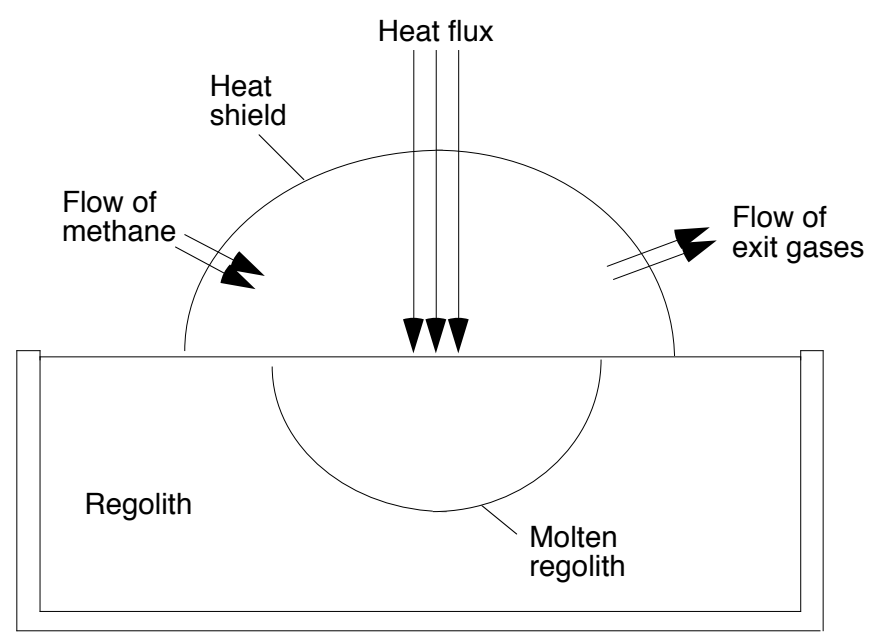

Figure 1. Sketch of the carbothermal process

\section{B. Governing equations}

We model the heating and melting of the regolith using the equations of heat transport by conduction and phase change. We neglect convective heat transfer in the melt. Convective flow in the melt is likely caused by temperature gradients due to natural convection and thermocapillary forces, as well as gravity-induced bubble motion when the reaction in the melt liberates gaseous carbon monoxide in it. Natural convection is likely to be weak since the melt is heated from above. When there is no reaction in the melt, bubble production is absent. Our model is restricted to such a scenario, and we will compare our predictions of melt mass with experiments without reactions. The effective themophysical properties of the regolith and the melt are treated to be different. A volume of regolith has a void fraction of nearly $40 \%$. Thus the regolith properties are quite different from those of a bulk material of the same chemical composition. In our formulation of the governing equations, the regolith and the melt are treated as a single material with temperature dependent properties. The latent heat of melting is also accommodated by the single material formulation by an enthalpy method wherein the specific heat of the material is equivalently altered in a narrow temperature range around the melting point. 
Since the void fraction in the regolith can be large, one can expect a large difference in the density between the regolith and the melt. One complication due to the density change is the accompanying volume change upon phase change - the melt will occupy a smaller volume than the amount of regolith from which it is formed. Thus in addition to tracking the interface between the melt and the unmolten regolith (the melting front), the free surface between the melt and the gas phase above it must be tracked because of the volume change, which complicates the solution considerably. At first, we will analyze the heat transfer permitting the density change between the regolith and the melt, but without considering the volume change. We will include the effects of volume change later on.

\section{Time-dependent temperature field}

The energy equation is written as follows.

$$
\rho C_{p} \frac{\partial T}{\partial t}=\nabla \cdot(k \nabla T)
$$

where $\rho=\rho_{\text {reg }}+\left(\rho_{\text {melt }}-\rho_{\text {reg }}\right) \mathcal{U}\left(T-T_{m}\right), k=k_{\text {reg }}+\left(k_{\text {melt }}-k_{\text {reg }}\right) \mathcal{U}\left(T-T_{m}\right), C_{p}=C_{p_{\text {reg }}}+\left(C_{p_{\text {melt }}}-\right.$ $\left.C_{p_{\text {reg }}}\right) \mathcal{U}\left(T-T_{m}\right)+\frac{\rho_{\text {reg }}}{\rho} \hat{L} \delta\left(T-T_{m}\right)$, and $\mathcal{U}(x)$ and $\delta(x)$ are the unit-step and delta functions, respectively, of argument $x$. In the computations, smooth numerical analogues for these functions are used.

The initial condition is:

$$
T=T_{a} \text { at } t=0
$$

The boundary conditions are:

$$
\begin{gathered}
-k \frac{\partial T}{\partial n}=\alpha_{\mathrm{abs}} q_{0}-\epsilon_{\mathrm{eff}} \sigma\left(T^{4}-T_{a}^{4}\right)-h\left(T-T_{a}\right) @ \text { Regolith surface impinged by heat flux } \\
-k \frac{\partial T}{\partial n}=-\epsilon_{\mathrm{eff}} \sigma\left(T^{4}-T_{a}^{4}\right)-h\left(T-T_{a}\right) @ \text { Regolith surface outside heat flux } \\
\frac{\partial T}{\partial r}=0 @ r=0 \text { (Axial symmetry) } \\
T=T_{a} \text { or } \frac{\partial T}{\partial n}=0 @ \text { Container boundary }
\end{gathered}
$$

Once the solution for the temperature field is known, the melting front is determined as the surface where $T=T_{m}$. The melt volume can then be obtained by a volume integral of the amount of material with temperature $T>T_{m}$.

\section{Steady-state considerations}

We consider the question whether a steady state can be achieved where the melt volume and temperature field in the melt and regolith do not change with time. We assume that the container boundaries are insulated. For a steady state to exist, the total amount of heat input into the melt (which equals the heat flux impinging the melt that is absorbed minus the heat flux lost to the ambient from the melt surface by radiation and to a much smaller extent by convection) must be equal to the amount of heat loss from the non-molten regolith surface (due to radiation and convection). The energy equation at steady state can be written as

$$
\nabla \cdot(k \nabla T)=0
$$

This equation is non-linear because the location of the melting front is unknown. Therefore, the regions in the domain where $k=k_{\text {melt }}$ and $k=k_{\text {reg }}$ are not known a priori. To overcome this issue, we use the well known Kirchhoff transformation.

$$
V(T)=\frac{1}{k_{\mathrm{melt}}} \int_{T_{a}}^{T} k(\theta) d \theta
$$

The energy equation is simplified to

$$
\nabla^{2} V=0
$$


The boundary conditions are

$$
\begin{gathered}
\frac{\partial V}{\partial n}=0 @ \text { Container boundary } \\
-k_{\text {melt }} \frac{\partial V}{\partial n}=\alpha_{\text {abs }} q_{0}-\epsilon_{\text {eff }} \sigma\left(T^{4}-T_{a}^{4}\right)-h\left(T-T_{a}\right) @ \text { Regolith surface impinged by heat flux } \\
-k_{\text {melt }} \frac{\partial V}{\partial n}=-\epsilon_{\text {eff }} \sigma\left(T^{4}-T_{a}^{4}\right)-h\left(T-T_{a}\right) @ \text { Regolith surface outside heat flux }
\end{gathered}
$$

where $\mathrm{T}$ in the above equations is the quantity

$$
\begin{gathered}
T=\frac{k_{\mathrm{melt}}}{k_{\mathrm{reg}}} V+T_{a} \quad \text { for } \quad V \leq \frac{k_{\mathrm{reg}}}{k_{\mathrm{melt}}}\left(T_{m}-T_{a}\right)\left(\text { or } T \leq T_{m}\right) \\
T=T_{m}+V-\frac{k_{\mathrm{reg}}}{k_{\mathrm{melt}}}\left(T_{m}-T_{a}\right) \quad \text { for } \quad V>\frac{k_{\mathrm{reg}}}{k_{\mathrm{melt}}}\left(T_{m}-T_{a}\right)\left(\text { or } T>T_{m}\right)
\end{gathered}
$$

While the problem is still non-linear because of the boundary conditions in Eqs (11) and (12), the energy equation has been rendered linear by the use of the Kirchhoff transformation. These equations are solved numerically for specified values of $k_{\mathrm{reg}}, k_{\mathrm{melt}}, T_{m}, T_{a}, \alpha_{\mathrm{abs}}, \epsilon_{\mathrm{eff}}, h$ and $q_{0}$.

\section{Volume change considerations}

As mentioned before, the regolith contains a substantial amount of void space and its density is quite a bit lower than a solid material of the same composition. The melt is expected to have a density similar to the solid material. Therefore, once the regolith melts, the volume occupied by the melt will be less than the volume of regolith from which it was formed. In the presence of gravity, the melt which is heavier sinks, and the melt free surface moves downward. The volume vacated by the heavier melt is occupied by the gas phase above it.

Strictly speaking, in order to analyze the effect of the melt volume change, the equations of fluid motion need to to be analyzed along with the energy equation to describe the motion on the surface of the melt and within it. In our model, however, we use an approximate formulation without analyzing the melt motion in detail. We have used the conduction/phase change formulation of the energy equation (Equations 1 to 6 ) where the location of the free surface between the melt and the gas phase above it is unknown and time dependent. In the numerical calculations, the free surface position is moved from its initial location by using either an interface velocity or displacement condition that are obtained by mass conservation upon phase change.

$$
\begin{gathered}
v_{n}=-\frac{\left(\rho_{\text {melt }}-\rho_{\text {reg }}\right)}{\rho_{\text {reg }} \pi R_{\text {melt }}^{2}} \frac{d V_{\text {melt }}}{d t} \text { for } T \geq T_{m} ; \quad v_{n}=0 \text { for } T<T_{m} \\
d_{n}=-\frac{\left(\rho_{\text {melt }}-\rho_{\text {reg }}\right)}{\rho_{\text {reg }} \pi R_{\text {melt }}^{2}} V_{\text {melt }} \text { for } T \geq T_{m} ; \quad d_{n}=0 \text { for } T<T_{m}
\end{gathered}
$$

where $V_{\text {melt }}$ and $R_{\text {melt }}$ are the instantaneous melt volume and melt radius on the free surface. These quantities are obtained by querying the instantaneous temperature field and demarcating the regions where the local temperature is greater than the melting point. As the free surface deforms the numerical grids are recalculated and the computations are carried forward in time using an Arbitrary Lagrangian Eulerian Scheme (ALE) with Winslow smoothing. ${ }^{5}$

\section{Results}

The values of the thermophysical properties we have used in the numerical calculations are given in Table 1. Many of the properties are not known precisely, and may not be the same for lunar regolith and its simulants such as JSC-1A. The properties used for the melt are the same as those for solid basalt rock from which regolith is formed. We have varied the values of the properties, chiefly the thermal conductivity, over a range in order to explore its influence on the melt mass. The lower value of the thermal conductivity of regolith is applicable when it is exposed to vacuum, such as on the lunar surface, and the value at room temperature and pressure for JSC-1A is around $0.2 \mathrm{~W} /(\mathrm{m} \mathrm{K}){ }^{6}$ The computations have been performed for three-dimensional axisymmetric situations using the software package COMSOL 3.5a. Results are described below for the temperature distribution and melt mass at steady state, their transient evolution without considering volume change, and finally how the melt mass is influenced by volume change. We also compare the numerical results with specialized results for transient one-dimensional conduction with phase change. 


\section{A. Steady state}

Figure 2 shows the temperature distribution and the location of the melting front marked as a red line at steady state, when the container boundaries are adiabatic. Figure 3 shows similar results when the container walls are maintained at a temperature $T=T_{a}=300 \mathrm{~K}$. In each figure, we show the computed results with $k_{\text {reg }}=0.01,0.2$ and $0.5 \mathrm{~W} /(\mathrm{m} \mathrm{K})$, with $k_{\text {melt }}=2.1 \mathrm{~W} /(\mathrm{m} \mathrm{K})$ in all cases. The conductivity of regolith covers the range from the lunar surface exposed to vacuum to that in the presence of a gas at ambient temperature and pressure. Equations (9) to (14) using the Kirchhoff transformation have been used in these calculations.

We see from Figures 2 and 3 that the thermal conductivity of regolith has a major role in the obtained melt volume, shown by the region with $T \geq 1400 \mathrm{~K}$ (the melt masses obtained are given in the figure legends). For a fixed thermal conductivity of the melt, the melt volume is inversely proportional to the thermal conductivity of the regolith. At steady state, a fixed amount of heat that enters the melt must be lost from the cold regolith surface outside the area of the beam of incident heat flux. When the regolith thermal conductivity is low, the temperature gradient in it must increase to transfer the heat from the melt front (which is at the melting point) to the regolith surface (which is nearly at the ambient temperature). Thus the melting front location must be closer to the cold regolith surface when its conductivity is low, and therefore the melt volume is larger. It is also seen from Figures 2 and 3 that when the regolith conductivity is relatively large $\left(k_{\mathrm{reg}}=0.2,0.5 \mathrm{~W} /(\mathrm{m} \mathrm{K})\right)$, the melt volume is less sensitive to the boundary condition on the container walls than for $k_{\text {reg }}=0.01 \mathrm{~W} /(\mathrm{m} \mathrm{K})$.

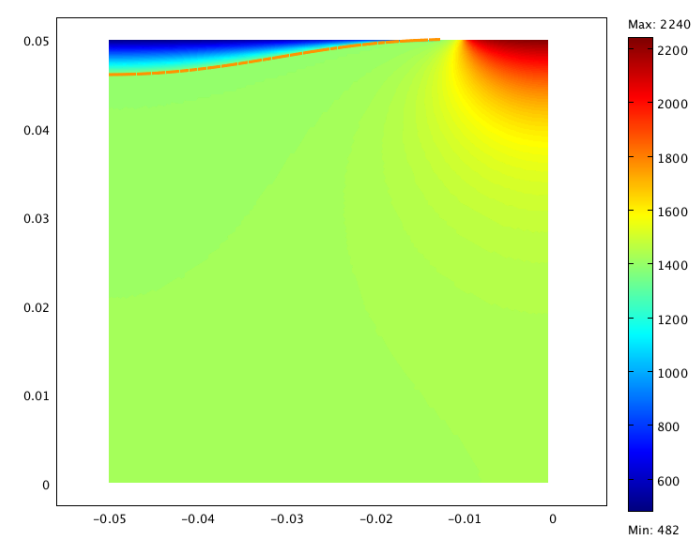

(a)

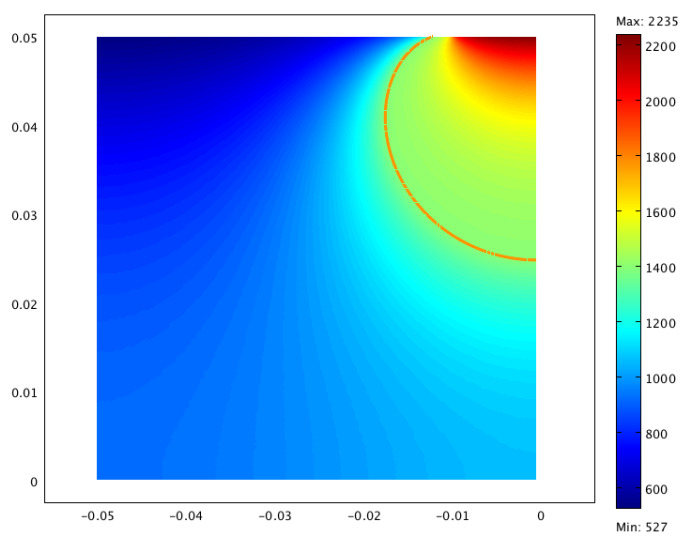

(b)

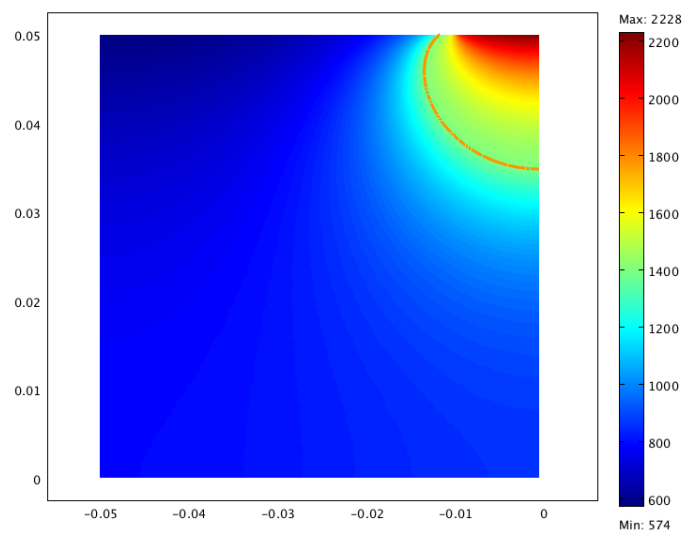

(c)

Figure 2. Temperature distribution and location of the melting front at steady state. $k_{\text {reg }}=$ (a) $0.01,(b) 0.2,(c) 0.5 \mathrm{~W} /(\mathrm{m} \mathrm{K}), k_{\text {melt }}=2.1 \mathrm{~W} /(\mathrm{mK}), \alpha_{\mathrm{abs}}=\epsilon_{\mathrm{eff}}=0.9, h=0$, heat flux beam diameter $=$ $0.75 \mathrm{in}, \mathrm{Q}=470 \mathrm{~W}, T_{a}=300 \mathrm{~K}$, container radius and depth $=5 \mathrm{~cm}$, adiabatic container boundaries. The melt masses obtained are (a) 1066 (b) 55 and (c) 17 grams. 


\begin{tabular}{|c|c|c|c|c|c|}
\hline & $\begin{array}{c}\text { Density } \\
\mathrm{kg} / \mathrm{m}^{\wedge} 3\end{array}$ & $\begin{array}{c}\text { Specific heat } \\
\mathrm{J} /(\mathrm{kg} \mathrm{K})\end{array}$ & $\begin{array}{c}\text { Thermal } \\
\text { conductivity } \\
\mathrm{W} /(\mathrm{m} \mathrm{K})\end{array}$ & $\begin{array}{c}\text { Melting point } \\
\mathrm{K}\end{array}$ & $\begin{array}{c}\text { Latent heat } \\
\mathrm{J} / \mathrm{kg}\end{array}$ \\
\hline $\begin{array}{c}\text { Regolith } \\
\text { Melt }\end{array}$ & 1800 & 840 & $0.01-0.5$ & 1400 & 435000 \\
\hline
\end{tabular}

Table 1: Thermophysical properties of regolith and melt.

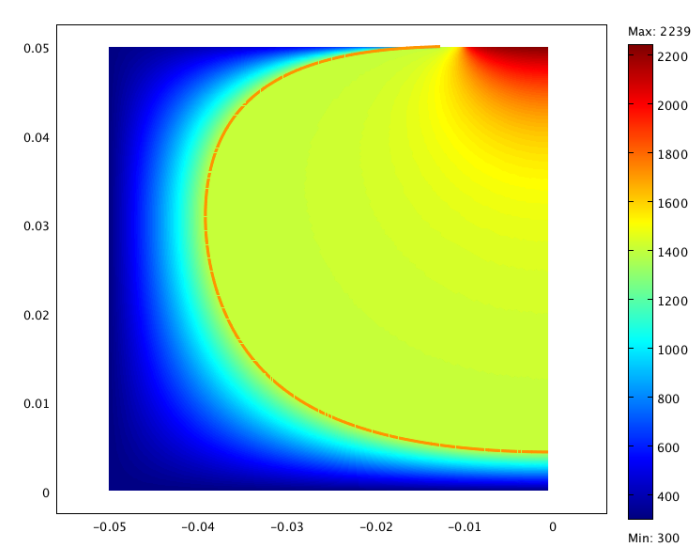

(a)

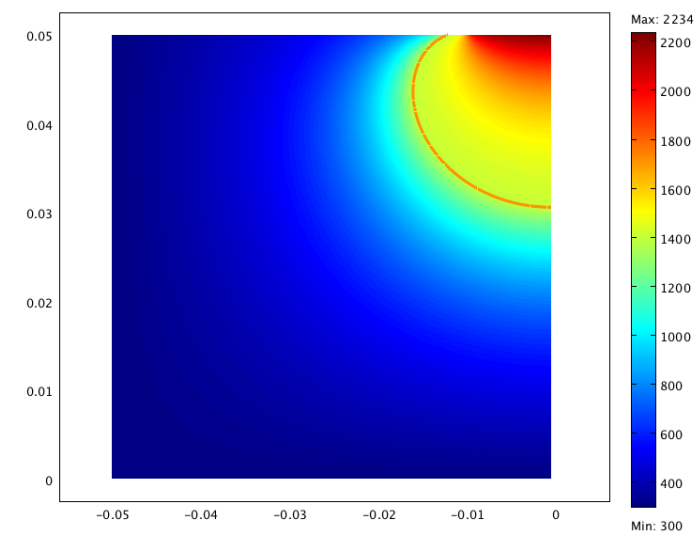

(b)

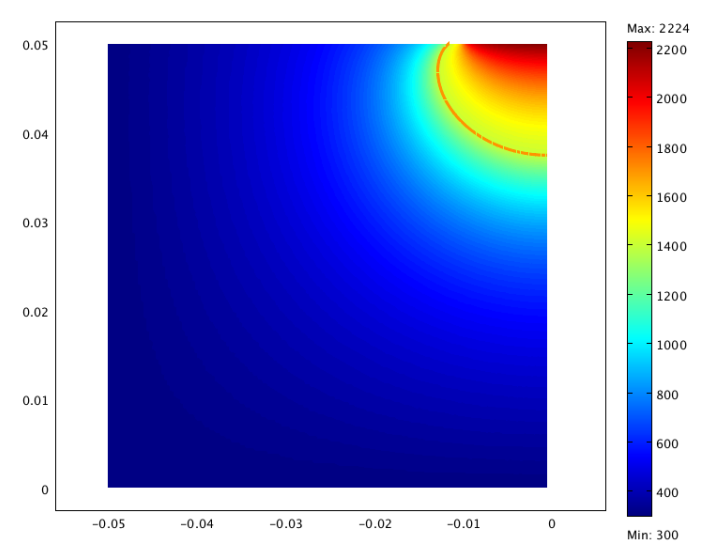

(c)

Figure 3. Temperature distribution and location of the melting front at steady state. $k_{\text {reg }}=$ (a) $0.01,(b) 0.2,(c) 0.5 \mathrm{~W} /(m K), k_{\text {melt }}=2.1 \mathrm{~W} /(m K), \alpha_{\text {abs }}=\epsilon_{\text {eff }}=0.9, h=0$, heat flux beam diameter $=$ $0.75 \mathrm{in}, \mathbf{Q}=470 \mathrm{~W}, T_{a}=300 \mathrm{~K}$, container radius and depth $=\mathbf{5} \mathrm{cm}$, container boundaries at $T=T_{a}$. The melt masses obtained are (a) 474 (b) 31 and (c) 13 grams.

\section{B. Transient melt growth}

Figures 4 and 5 show the temperature distribution and the melting front location as they evolve with time for $k_{\text {reg }}=0.05$ and $0.5 \mathrm{~W} /(\mathrm{m} \mathrm{K})$, respectively, with $k_{\text {melt }}=2.1 \mathrm{~W} /(\mathrm{m} \mathrm{K})$. We have used a somewhat larger value for $k_{\text {reg }}$ at the low end than in the results discussed at steady-state because for smaller values of $k_{\text {reg }}$, the numerical calculations exhibited oscillatory temperature fields near the melting front, and the front shape was not smooth. At the final time step $t=4800 \mathrm{~s}$, we see in Figure 4 that the melt growth is still evolving, while in Figure 5 for a larger regolith conductivity, the melt shape is quite close to a steady state. In both Figures 4 and 5, we see that melt radius increases with depth below the surface at first, attains a maximum radius, and then gradually decreases to zero at the location where the melt depth is a maximum. For both melts, these features of the melt shape are evident at all the times shown in the figures. The melt radius on the surface of the melt is constrained by the surface heat loss and is only slightly larger than the radius of the beam of heat flux that impinges the surface (beam diameter is $0.75 \mathrm{in}$ ). The surface melt radius achieves its steady value rather quickly (on the order of a minute) after the heat flux is turned on. 


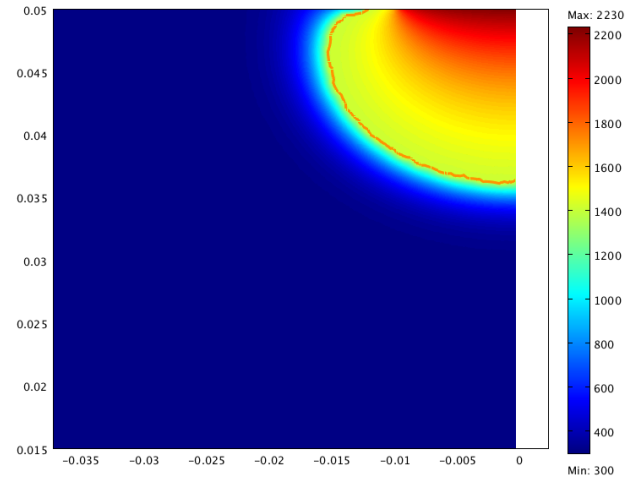

(a)

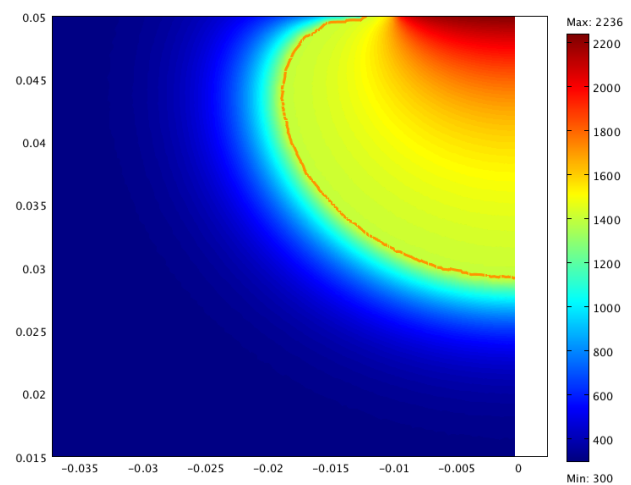

(c)

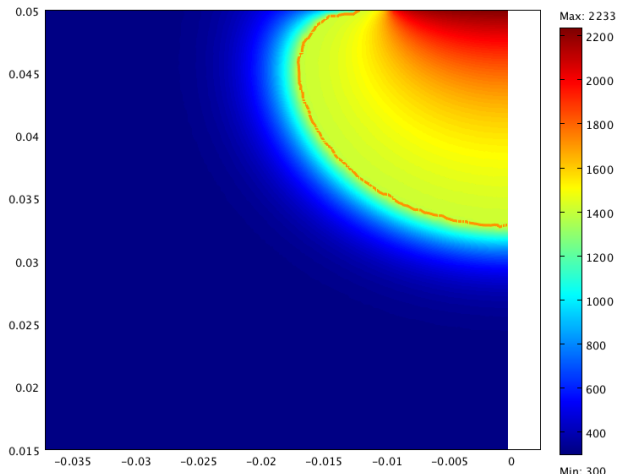

(b)

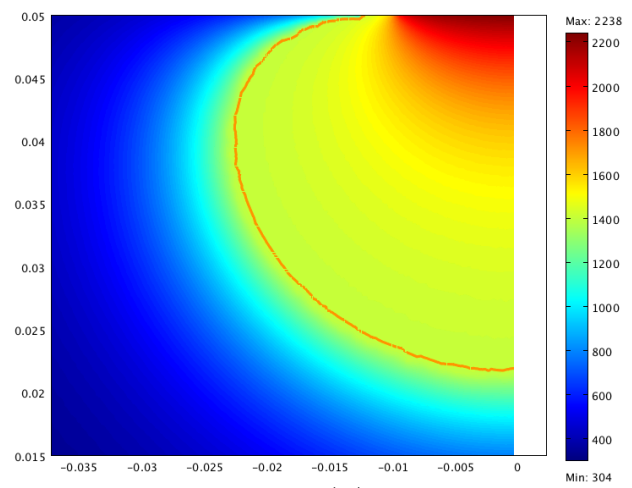

(d)

Figure 4. Temperature distribution and location of the melting front for a growing melt at (a) $t=300 \mathrm{~s}$, (b) $\mathbf{t}=600 \mathbf{s}$, (c) $\mathbf{t}=\mathbf{1 2 0 0} \mathbf{s}$ (d) $\mathbf{t}=4800 \mathbf{s} . \quad k_{\text {reg }}=0.05, k_{\text {melt }}=2.1 \mathrm{~W} /(m K), \alpha_{\text {abs }}=\epsilon_{\text {eff }}=0.9, h=0$, heat flux beam diameter $=0.75 \mathrm{in}, \mathrm{Q}=470 \mathrm{~W}, T_{a}=300 \mathrm{~K}$, container radius and depth $=5 \mathrm{~cm}$, adiabatic container boundaries. A $3.5 \times 3.5 \mathrm{~cm}$ region is shown. The melt masses obtained are (a) 20 (b) 31 (c) 46 and (d) 91 grams.

Figure 6 shows the time evolution of the temperature on the surface of the melt at $r=0$ for $k_{\text {reg }}=0.05$ and $0.5 \mathrm{~W} /(\mathrm{m} \mathrm{K})$. After the heat flux is turned on, the surface temperature rapidly rises from its initial value of $300 \mathrm{~K}$, and achieves the melting point of $1400 \mathrm{~K}$ in approximately $1 \mathrm{~s}$. The surface temperature rises close to $2200 \mathrm{~K}$ in the time scale on the order of a minute, and thereafter changes slowly with time $\left(T_{s}=2215 \mathrm{~K}\right.$ at $100 \mathrm{~s}$ and $2238 \mathrm{~K}$ at $4800 \mathrm{~s}$ for $\left.k_{\text {reg }}=0.05 \mathrm{~W} /(\mathrm{m} \mathrm{K})\right)$. The maximum surface temperature that can ever be achieved is obtained by balancing the incident heat flux and the surface heat loss, ignoring conduction into the melt. Neglecting convective heat loss, the maximum surface temperature can be computed as $T_{s}=\left(\alpha_{\mathrm{abs}} q_{0} /(\epsilon \sigma)+T_{a}^{4}\right)^{1 / 4}=2322 \mathrm{~K}$. The ultimate surface temperature achieved (Figure 6$)$ is somewhat less due to the heat flux conducted into the melt, not accounted for in the heat balance in computing $T_{s}$.

Figure 7 shows the predicted melt mass and how it compares with the masses obtained from test data. ${ }^{7}$ These tests were performed in air and there were no chemical reactions in the melt. In obtaining the predictions, we have varied the thermal conductivity values of the regolith and melt in a small range to determine the sensitivity of the melt mass to these values. At $t=4800 \mathrm{~s}$, the predicted melt mass is in the range from approximately $10 \mathrm{~g}$ (for $k_{\text {reg }}=0.5$ and $k_{\text {melt }}=1.5 \mathrm{~W} /(\mathrm{m} \mathrm{K})$ ) to $30 \mathrm{~g}$ for $k_{\text {reg }}=0.2$ and $k_{\text {melt }}=2.0 \mathrm{~W} /(\mathrm{m}$ $\mathrm{K})$ ). It appears that for this test data, $k_{\text {reg }}=0.5$ and $k_{\text {melt }}=2.0 \mathrm{~W} /(\mathrm{m} \mathrm{K})$ predicts the melt mass well for melt times greater than $1000 \mathrm{~s}$. The value of $k_{\text {reg }}$ is somewhat larger than the measurements in Ref [6] at room temperature, but these authors have reported an increase in the apparent thermal conductivity due to stresses created by thermal expansion of the simulant particles against the rigid chamber wall. For reasons that are unknown, a lower melt conductivity $\left(k_{\text {melt }}=1.5 \mathrm{~W} /(\mathrm{m} \mathrm{K})\right)$ appears to fit the data better for earlier times. Perhaps $k_{\text {reg }}$ and $k_{\text {melt }}$ are temperature dependent, or the melts at earlier times are not well-formed and have regions of regolith particles trapped within them. In generating the results shown in Figure 7, we have assumed that the container walls are adiabatic and there is no convective heat loss from the surfaces of the melt and the regolith to the gas phase above them. We have used an emissivity of $\epsilon=0.9$ for these surfaces, as a radiation shield was not used in the tests from which the data was obtained.

\section{Effect of volume change}

Figure 8 shows the time evolution of the temperature distribution, and the locations of the melting front and the free surface between the melt and the gas phase above it. The free surface motion is modeled using the 


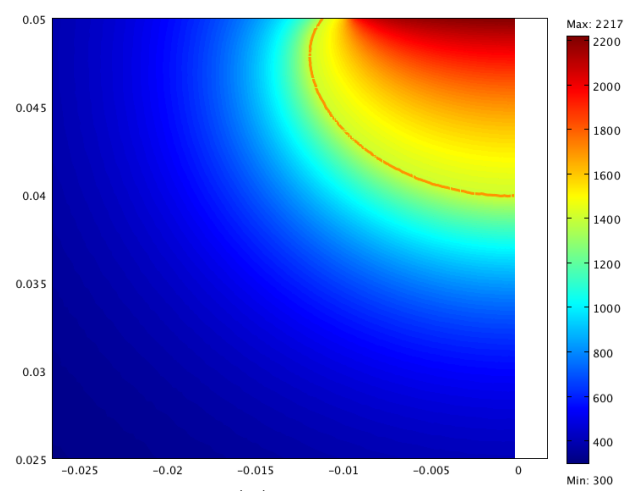

(a)

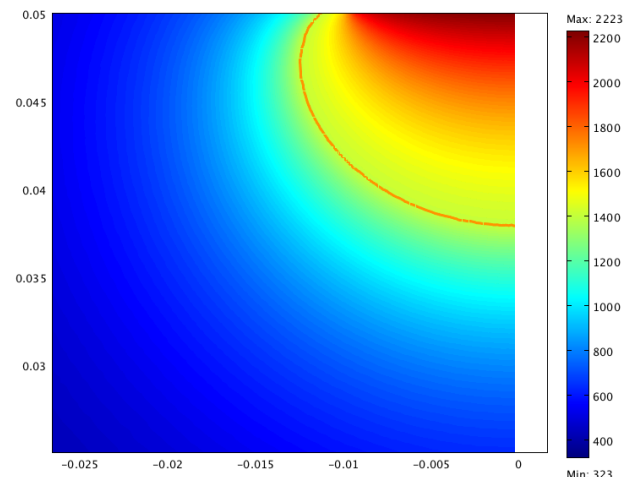

(c)

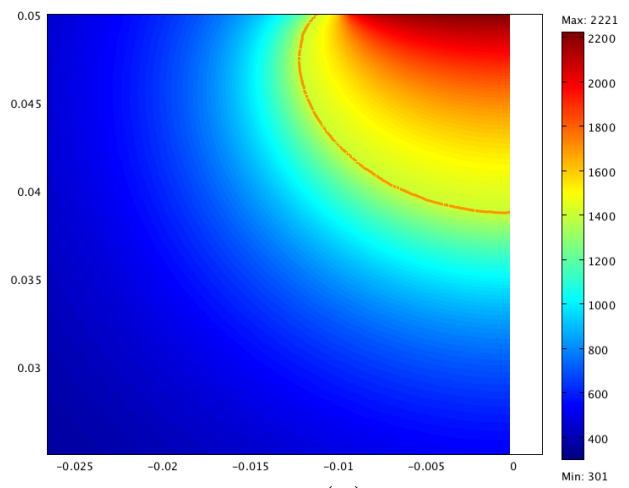

(b)

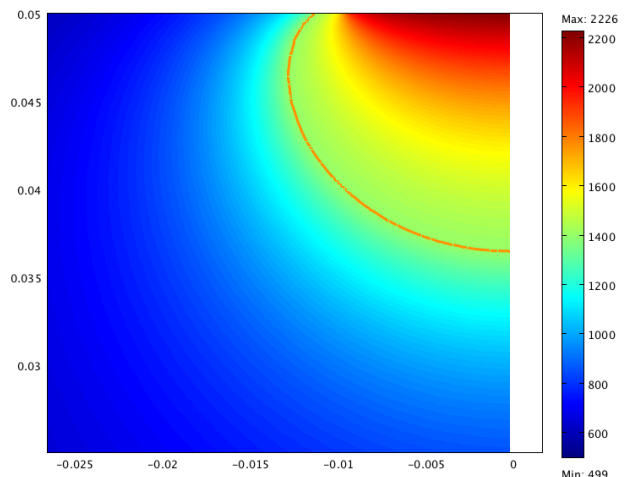

(d)

Figure 5. Temperature distribution and location of the melting front for a growing melt at (a) $t=300 \mathrm{~s}$, (b) $\mathbf{t}=600 \mathrm{~s},(\mathbf{c}) \mathbf{t}=1200 \mathrm{~s}$ (d) $\mathbf{t}=4800 \mathrm{~s}$. $k_{\text {reg }}=0.5, k_{\text {melt }}=2.1 \mathrm{~W} /(\mathrm{m} K), \alpha_{\mathrm{abs}}=\epsilon_{\text {eff }}=0.9, h=0$, heat flux beam diameter $=0.75 \mathrm{in}, \mathrm{Q}=470 \mathrm{~W}, T_{a}=300 \mathrm{~K}$, container radius and depth $=5 \mathrm{~cm}$, adiabatic container boundaries. A $2.5 \times 2.5 \mathrm{~cm}$ region is shown. The melt masses obtained are (a) 9 (b) 11 (c) 12 and (d) 14 grams.

velocity boundary condition (Eq (15)). Similar results using a displacement condition for the free surface (Eq (16)) are shown in Figure 9. The predicted shapes of the void region at the rim of the melt region are different between these two results, with the velocity condition predicting a gradual shape change in the rim, and the displacement condition shows a sharper change. In both calculations we have used $T=T_{a}=300$ $\mathrm{K}$ as the boundary condition on the container walls. Also, a convective heat transfer coefficient $h=10$ $\mathrm{W} /\left(\mathrm{m}^{2} \mathrm{~K}\right)$ has been used on the regolith and melt surfaces in contact with the gas phase. While the melt free surface moves, the heat flux is assumed to continuously shine on it and impinge perpendicularly with a constant beam diameter of 0.75 in (beam radius is $0.0095 \mathrm{~m}$ ). Figures 8 and 9 show a large void volume (occupied by the gas phase) as the regolith melts, due to the change in volume on melting. Conservation of mass yields that $\left(V_{\text {void }}+V_{\text {melt }}\right) \rho_{\text {reg }}=V_{\text {melt }} \rho_{\text {melt }} \Rightarrow \frac{V_{\text {void }}}{V_{\text {void }}+V_{\text {melt }}}=\frac{\rho_{\text {melt }}-\rho_{\text {reg }}}{\rho_{\text {melt }}}=\frac{2850-1800}{2850}=0.37$.

The shape of the predicted melt free surface in Figures 8 and 9 is worthy of discussion. In the presence of a gravitational body force, the free surface of a liquid is expected to be horizontal under static conditions. Deformations to the shape of the free surface can occur due to hydrodynamic stresses, liquid rotation, and capillary forces due to the effects of surface tension, especially near the meniscus region where the free surface comes into contact with a solid. Note that none of these effects have been included in our model. The melt free surface is not horizontal in the results shown in Figures 8 and 9 (the melt is the region with $T>1400 \mathrm{~K}$ ) near its outer rim. While we have restricted the free surface deformation to be strictly vertical in using the conditions in $\mathrm{Eq}(15)$ and $\mathrm{Eq}$ (16), the results show that effect of gravity in maintaining a horizontal free surface is not strongly implemented by these conditions. The calculations shown in Figure 9 with a deformation condition on the free surface seem to be better in this regard, and predict a smaller deviation from a flat shape for the melt free surface. We believe, in hindsight, that the approximate way in which we have used Eq (15) or Eq (16) to model the motion of the free surface to accommodate the volume change, without calculating the velocity field in the melt in detail (using the Navier-Stokes equations) and its effect on the heat transfer in the melt are responsible for the incorrect shape of the melt free surface that is predicted. 


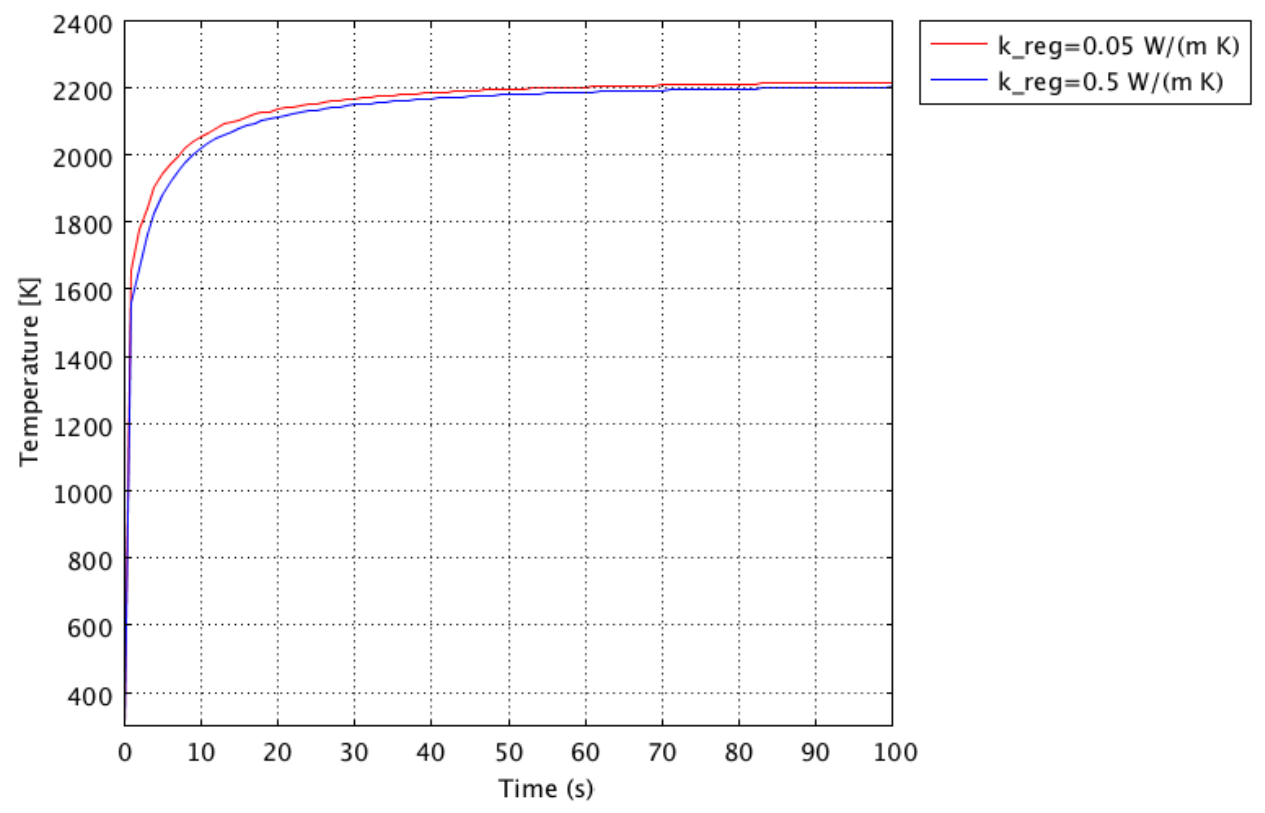

Figure 6. Variation of the surface temperature at $r=0$ with time

Figure 10 shows the predicted melt masses including the effect of volume change and how they compare with the test data. The velocity condition $(\mathrm{Eq}(15))$ has been used in these results, but representative calculations show that the masses obtained using Eq (15) or Eq (16) are almost identical. Unlike in Figure 7, a single curve with $k_{\text {reg }}=0.5$ and $k_{\text {melt }}=2 \mathrm{~W} /(\mathrm{m} \mathrm{K})$ does not appear to represent the test data for $t>1000 \mathrm{~s}$. This data is adequately bounded by predictions with $k_{\text {melt }}$ in the range 1.8 to $2.0 \mathrm{~W} /(\mathrm{m} \mathrm{K})$. The data at earlier times is predicted accurately with $k_{\text {reg }}=0.5$ and $k_{\text {melt }}=1.2 \mathrm{~W} /(\mathrm{m} \mathrm{K})$, compared with $k_{\text {reg }}=0.5$ and $k_{\text {melt }}=1.5 \mathrm{~W} /(\mathrm{m} \mathrm{K})$ in Figure 7 . Note that in Figure 10 the container walls are at a fixed temperature and the surface convective heat transfer coefficient $h=10 \mathrm{~W} /\left(\mathrm{m}^{2} \mathrm{~K}\right)$, while in Figure 7 the container walls are adiabatic and $h=0$. In general, the volume change appears to result in a slightly larger melt mass for a fixed $k_{\text {reg }}$ and $k_{\text {melt }}$ compared to predictions that do not consider the volume change. Also, the predicted melt mass curves are flatter for larger times, indicating that the volume change tends to somewhat shorten the time taken to achieve steady state. It is likely due to the increase in radiative loss resulting from the increase in surface area of the melt and hot regolith surfaces that are evident in Figures 8 and 9.

\section{Comparison with one-dimensional calculations}

Carslaw and Jaeger ${ }^{8}$ provide a solution for a one-dimensional phase-change heat transfer including the effects of conduction and convection induced by a density change. They assume that the temperature of the surface of the solid is held fixed at a constant value above the melting point, for all time. They derive an analytical solution for the location of the melting front as a function of time, which is given below.

$$
X=2 \lambda \sqrt{\kappa_{\text {reg }} t}
$$

where $\lambda$ is determined from

$$
\frac{\exp \left(-\lambda^{2}\right)}{\operatorname{erfc} \lambda}+\lambda \sqrt{\pi} \frac{\hat{L}}{C_{p_{\text {reg }}}\left(T_{m}-T_{a}\right)}=\frac{k_{\text {melt }}}{k_{\text {reg }}} \sqrt{\frac{\kappa_{\text {reg }}}{\kappa_{\text {melt }}}}\left(\frac{T_{s}-T_{m}}{T_{m}-T_{a}}\right) \frac{\exp \left(-\lambda^{2} \frac{\rho_{\text {reg }}^{2} \kappa_{\text {reg }}}{\rho_{\text {melt }}^{2} \kappa_{\text {melt }}}\right)}{\left[1-\operatorname{erfc}\left(\lambda \frac{\rho_{\text {reg }} \sqrt{\kappa_{\text {reg }}}}{\rho_{\text {melt }} \sqrt{\kappa_{\text {melt }}}}\right)\right]}
$$

The surface temperature $T_{s}$ is determined balancing the impinging heat flux and the surface radiative loss as

$$
T_{s}=\left(\frac{\alpha_{\mathrm{abs}} Q}{\pi R_{\text {beam }}^{2} \epsilon \sigma}+T_{a}^{4}\right)^{1 / 4}
$$

We find that the melt mass calculated from these equations is much larger (by about a factor of five at $t=4800 \mathrm{~s}$ ) compared with the experimental data shown in Figure 7. This is likely due to the fact that the 


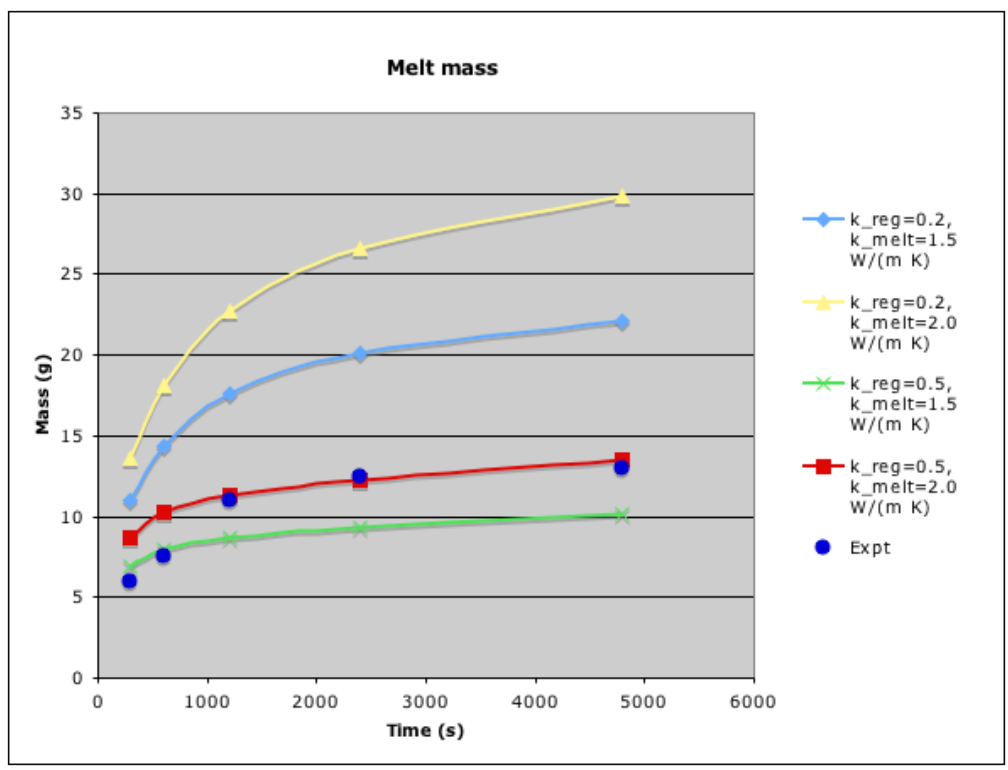

Figure 7. Comparison of experimental and calculated melt mass

one-dimensional model fails to capture the heat loss from the molten region to the regolith surrounding it. Furthermore, in the absence of the lateral heat loss, there is no steady state that is predicted. Therefore the one-dimensional analysis is of limited value and likely useful for only very short times after the start of melting.

\section{Conclusion}

In this study, we have analyzed the time-dependent volume of a melt zone that is generated when a portion of the surface of a bed of regolith is subjected to a constant heat flux, and there is radiative heat loss from the melt and regolith surfaces. Under these conditions, we find a steady-state to exist with the melt volume being inversely related to the thermal conductivity of the regolith. The transient evolution of melting has been performed with and without considering the effect of volume change due to melting. The predicted melt masses have been compared to test data, and we find that thermal conductivities of 0.5 and $2 \mathrm{~W} /(\mathrm{m}$ $\mathrm{K})$ for the regolith and melt, respectively, adequately represent the data.

\section{References}

${ }^{1}$ G.B. Sanders, W.E. Larson, K.R. Sacksteder and C.A. Mclemore, "NASA In-Situ Resource Utilization (ISRU) Project Development \& Implementation," Space 2008 Conference and Exposition, September 2008, San Diego, California.

${ }^{2}$ S.D. Rosenberg, R.L. Beegle, Jr, G.A. Guter, F.E., Miller, M. Rothenberg, The onsite manufacture of propellant oxygen from lunar resources, In NASA. Johnson Space Center, Space Resources, Volume 3: Materials, 162-185, 1991 (SEE N93-16875 05-91).

${ }^{3}$ ORBITEC, "Carbothermal Reduction of Lunar Regolith," Phase 1 Final Report OTC-GS0167-FR-06-1, Orbital Technologies Corporation (ORBITEC), Madison, Wisconsin, USA, 29 September 2006.

${ }^{4}$ R. Balasubramaniam, S. Gokoglu and U. Hegde, "The reduction of lunar regolith by carbothermal processing using methane," International Journal of Mineral Processing, Vol. 96, 54-61, 2010.

${ }^{5}$ COMSOL 3.5a, Comsol Inc., Burlington, Massachusetts, www.comsol.com.

${ }^{6}$ Z.G. Yuan and J.E. Kleinhenz, "Measurement of Apparent Thermal Conductivity of JSC-1A Under Ambient Pressure," AIAA 2011-6097, 49 ${ }^{\text {th }}$ AIAA Aerospace Sciences Meeting, Orlando, Florida, January 2011.

${ }^{7}$ R. J. Gustafson, B. C. White, and M. J. Fidler, "2010 Field Demonstration of the Solar Carbothermal Regolith Reduction Process to Produce Oxygen," AIAA 2011-434, $49^{\text {th }}$ AIAA Aerospace Sciences Meeting, Orlando, Florida, January 2011.

${ }^{8}$ H.S. Carslaw and J.C. Jaeger, "Conduction of Heat in Solids," Oxford University Press, 1959. 


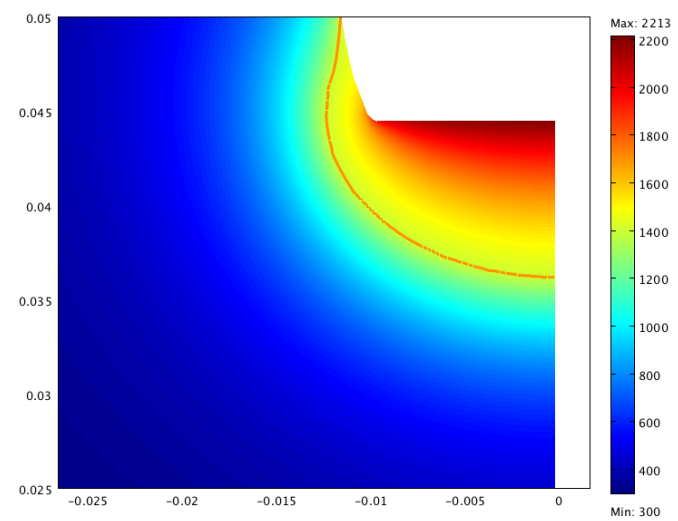

(a)

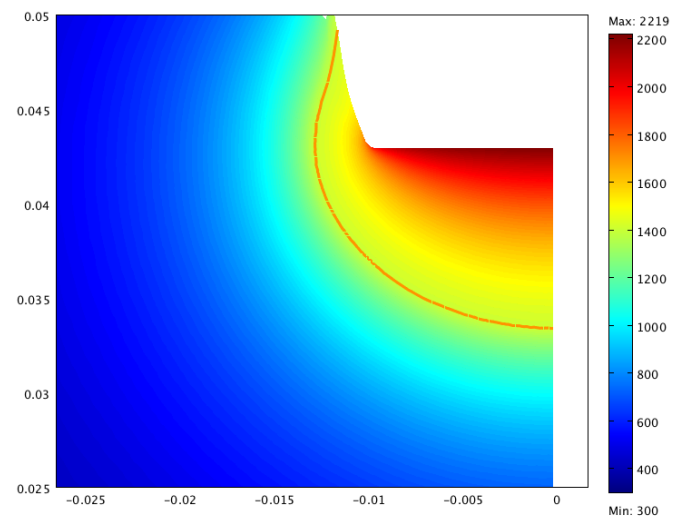

(c)

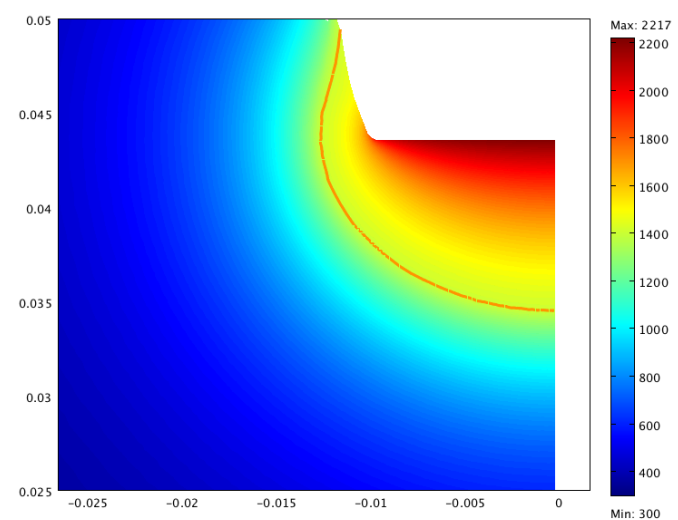

(b)

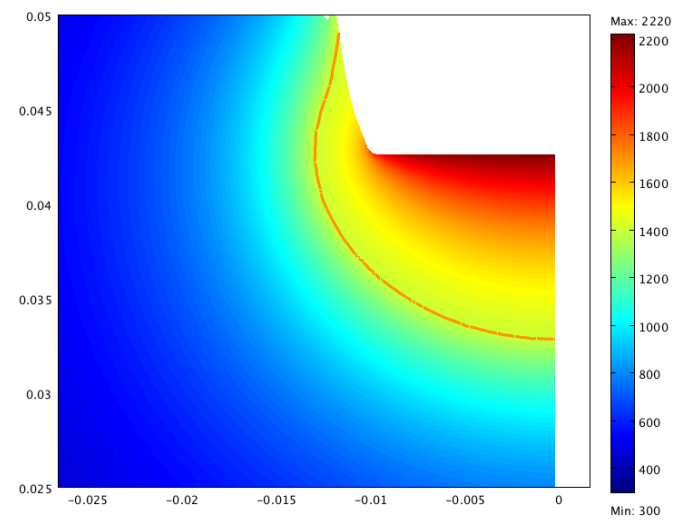

(d)

Figure 8. Temperature distribution and location of the melting front for a growing melt at (a) $t=300 \mathrm{~s}$, (b) $\mathbf{t}=600 \mathrm{~s},(\mathbf{c}) \mathbf{t}=\mathbf{1 2 0 0} \mathbf{s}$ (d) $\mathbf{t}=4800 \mathrm{~s} . k_{\text {reg }}=0.5, k_{\text {melt }}=2.1 \mathrm{~W} /(\mathrm{m} \mathrm{K}), \alpha_{\text {abs }}=\epsilon_{\text {eff }}=0.9, h=10 \mathbf{W} /(\mathbf{m ~ K})$, heat flux beam diameter $=0.75 \mathrm{in}, \mathrm{Q}=470 \mathrm{~W}, T_{a}=300 \mathrm{~K}$, container radius and depth $=5 \mathrm{~cm}$, container boundaries at $T=T_{a}$. Velocity condition (Eq 15) used for the motion of the free surface. A $2.5 \times 2.5 \mathrm{~cm}$ region is shown. The melt masses obtained are (a) 10 (b) 12 (c) 13 and (d) 14 grams. 


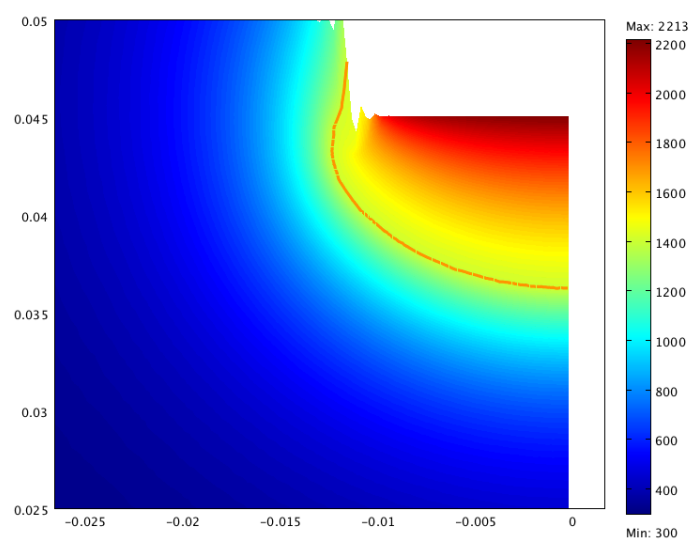

(a)

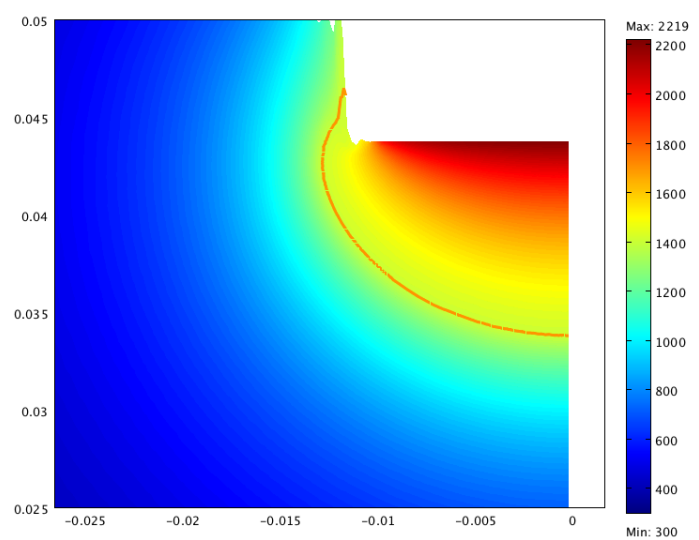

(c)

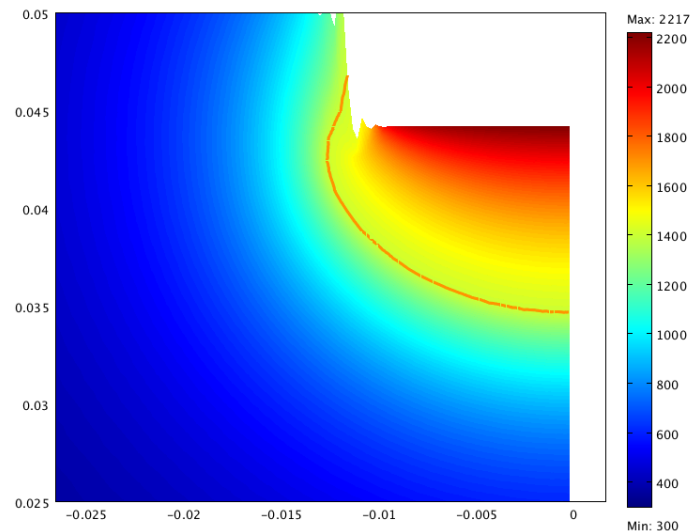

(b)

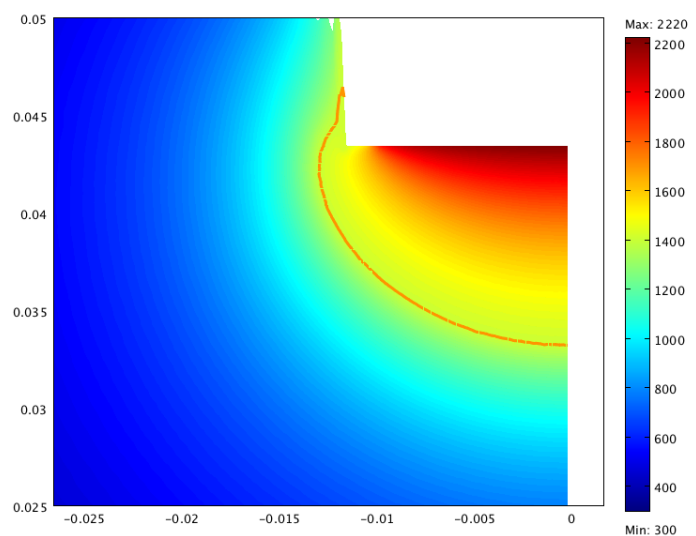

(d)

Figure 9. Temperature distribution and location of the melting front for a growing melt at (a) $t=300 \mathrm{~s}$, (b) $\mathbf{t}=600 \mathrm{~s},(\mathbf{c}) \mathbf{t}=1200 \mathrm{~s}$ (d) $\mathbf{t}=4800 \mathrm{~s} . k_{\mathrm{reg}}=0.5, k_{\text {melt }}=2.1 \mathrm{~W} /(\mathrm{mK}), \alpha_{\mathrm{abs}}=\epsilon_{\text {eff }}=0.9, h=10 \mathbf{W} /(\mathbf{m ~ K})$, heat flux beam diameter $=0.75 \mathrm{in}, \mathrm{Q}=470 \mathrm{~W}, T_{a}=300 \mathrm{~K}$, container radius and depth $=5 \mathrm{~cm}$, container boundaries at $T=T_{a}$. Displacement condition (Eq 16) used for the motion of the free surface. A $2.5 \times 2.5 \mathrm{~cm}$ region is shown. The melt masses obtained are (a) 10 (b) 12 (c) 13 and (d) 14 grams.

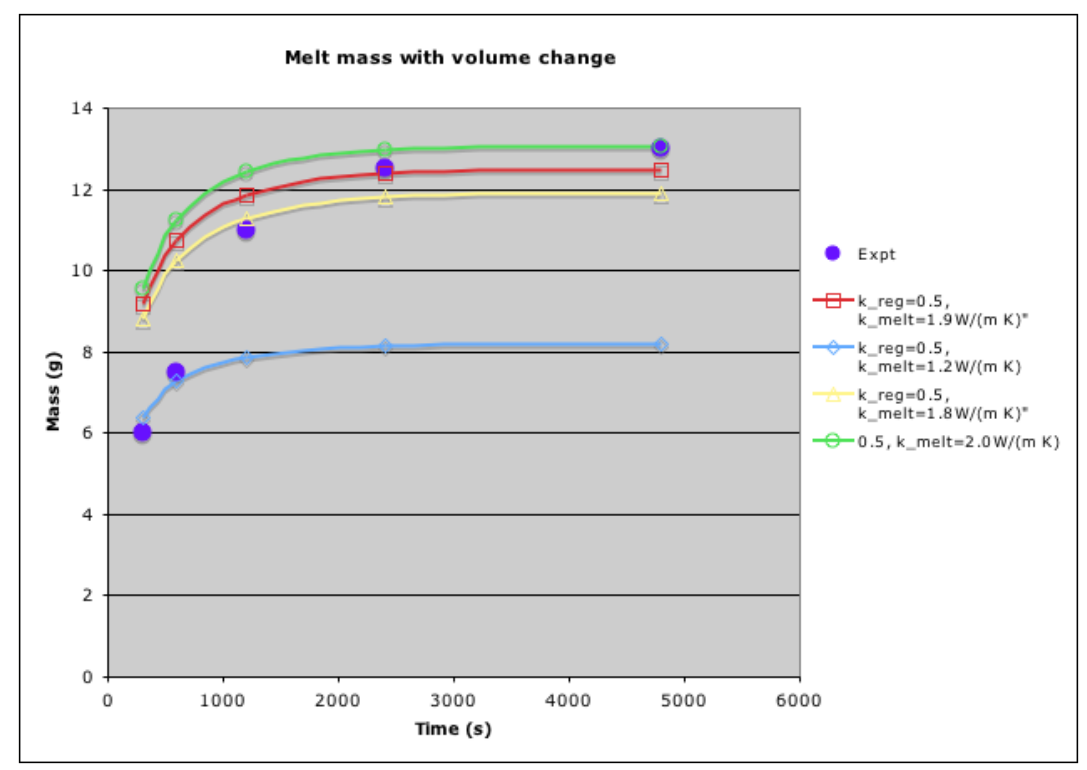

Figure 10. Comparison of experimental and calculated melt mass with the effect of volume change 


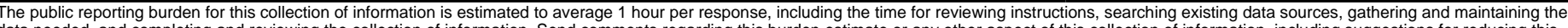

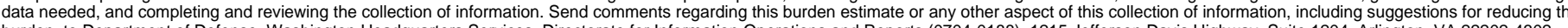
burden, to Department of Defense, Washington Headquarters Services, Directorate for Information Operations and Reports (0704-0188), 1215 Jefferson Davis Highway, Suite 1204, Arlington, VA 22202-4302.

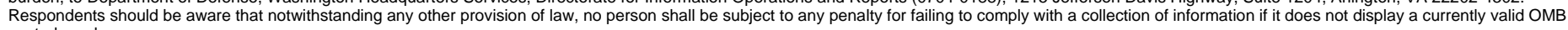
control number.

PLEASE DO NOT RETURN YOUR FORM TO THE ABOVE ADDRESS.

\begin{tabular}{|l|l|l}
\hline 1. REPORT DATE (DD-MM-YYYY) & 2. REPORT TYPE & 3. DATES COVERED (FrOm - TO)
\end{tabular}

\begin{tabular}{l|l} 
01-05-2012 & Technical Memorandum
\end{tabular}

\section{TITLE AND SUBTITLE}

Modeling of Melt Growth During Carbothermal Processing of Lunar Regolith

\section{5a. CONTRACT NUMBER}

5b. GRANT NUMBER

5c. PROGRAM ELEMENT NUMBER

6. AUTHOR(S)

Balasubramaniam, R.; Gokoglu, S.; Hegde, U.

\section{5d. PROJECT NUMBER}

5e. TASK NUMBER

5f. WORK UNIT NUMBER

WBS 387498.04.01.05.02.03

\section{PERFORMING ORGANIZATION NAME(S) AND ADDRESS(ES)}

National Aeronautics and Space Administration

John H. Glenn Research Center at Lewis Field

8. PERFORMING ORGANIZATION REPORT NUMBER

E-18171

Cleveland, Ohio 44135-3191

9. SPONSORING/MONITORING AGENCY NAME(S) AND ADDRESS(ES)

National Aeronautics and Space Administration

Washington, DC 20546-0001

\section{SPONSORING/MONITOR'S ACRONYM(S) \\ NASA}

\section{SPONSORING/MONITORING}

REPORT NUMBER

NASA/TM-2012-217440

\section{DISTRIBUTIONIAVAILABILITY STATEMENT}

Unclassified-Unlimited

Subject Category: 31

Available electronically at http://www.sti.nasa.gov

This publication is available from the NASA Center for AeroSpace Information, 443-757-5802

\section{SUPPLEMENTARY NOTES}

\section{ABSTRACT}

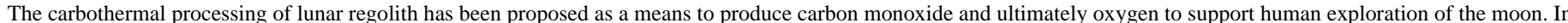

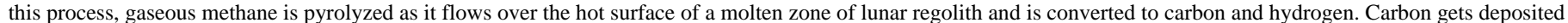

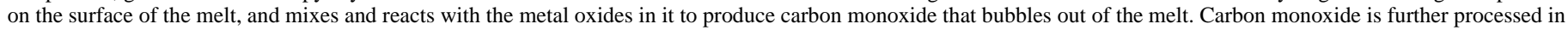

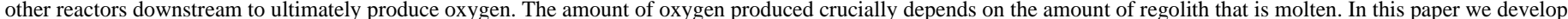

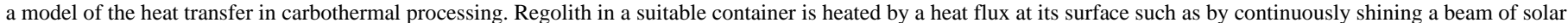

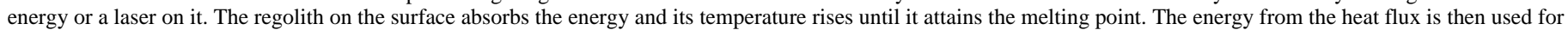

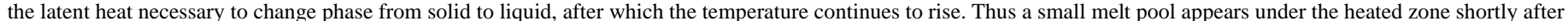
the heat flux is turned on. As time progresses, the pool absorbs more heat and supplies the energy required to melt more of the regolith, and the size of the molten zone

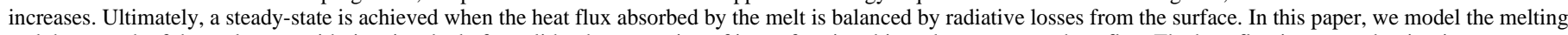
and the growth of the melt zone with time in a bed of regolith when a portion of its surface is subjected to a constant heat flux. The heat flux is assumed to impinge on a

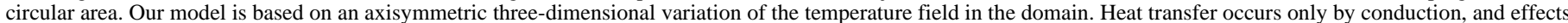

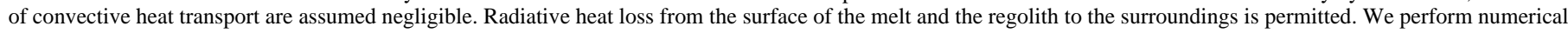
computations to determine the shape and the mass of the melt at steady state and its time evolution. We first neglect the volume change upon melting, and subsequently

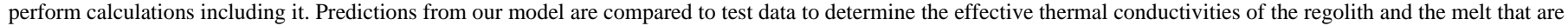
compatible with the data.

15. SUBJECT TERMS

Water extraction; Hydrogen reduction; ISRU; Lunar regolith simulant; Lunar regolith; Lunar simulant

\begin{tabular}{|l|l|l|l|c|l|}
\hline \multicolumn{2}{|l|}{ 16. SECURITY CLASSIFICATION OF: } & $\begin{array}{l}\text { 17. LIMITATION OF } \\
\text { ABSTRACT }\end{array}$ & $\begin{array}{l}\text { 18. NUMBER } \\
\text { OF } \\
\text { PAGES }\end{array}$ & $\begin{array}{l}\text { 19a. NAME OF RESPONSIBLE PERSON } \\
\text { STI Help Desk (email:help@sti.nasa.gov) }\end{array}$ \\
\cline { 1 - 2 } $\begin{array}{l}\text { a. REPORT } \\
\text { U }\end{array}$ & $\begin{array}{l}\text { b. ABSTRACT } \\
\text { U }\end{array}$ & $\begin{array}{l}\text { c. THIS } \\
\text { PAGE } \\
\text { U }\end{array}$ & UU & 20 & $\begin{array}{l}\text { 19b. TELEPHONE NUMBER (include area code) } \\
\text { 4t43-757-5802 }\end{array}$ \\
\hline
\end{tabular}



